
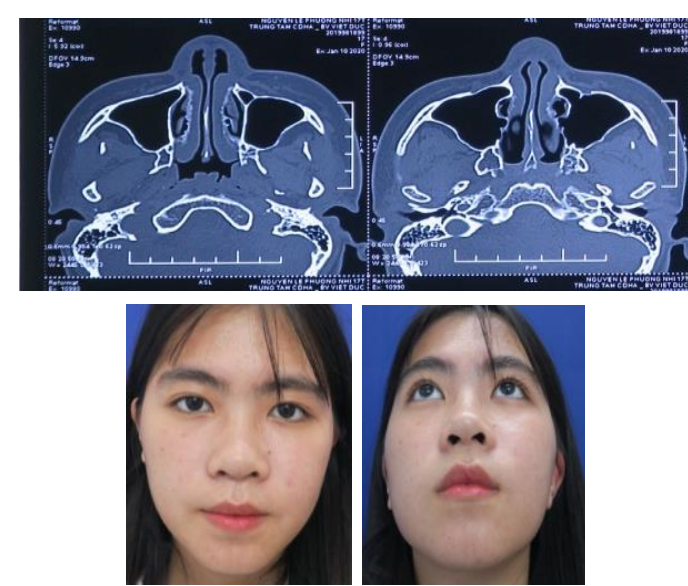

Hình 2. Sự cân đối trên phim và lâm sàng của bênh nhân sau phẫu thuât

Về chức năng, gãy xương gò má ít ảnh hưởng tới chức năng của bệnh nhân. Chủ yếu là tình trạng há miệng hạn chế do sưng nề, đau và kẹt cớ hoặc mỏm vẹt. Theo dõi sau phẫu thuật, chức năng cải thiện rõ rệt ở thời điểm 3 tháng so với ngay sau mổ. Gãy xương gò má ảnh hưởng nhiều tới thẩm mỹ, do mất tính cân xứng của khuôn mặt. Trong nghiên cứu của chúng tôi, sau 3 tháng có $95 \%$ bênh nhân đạt kết quả tốt, thời điểm này không còn ảnh hưởng bởi sưng nề do phẫu thuật. Các bệnh nhân sau khám đều hài lòng với kết quả sau điều trị.

\section{KẾT LUÂNN}

Qua điều trị 20 bệnh nhân gãy xương gò má, chúng tôi nhận thấy nẹp vít tự tiêu có thể áp dụng an toàn cho các trường hợp gãy gò má không phức tạp thay thế cho nẹp vít kim loại, mang lại kết quả tốt cả về chức năng và thẩm mỹ.

\section{TÀI LIỆU THAM KHẢO}

1. Trần Văn Trường, Trương Mạnh Dũng (2000). Tình hình chấn thương hàm mặt tại Viện Răng Hàm Măt Hà Nôi trong 11 năm (1988-1998) trên 2149 bệnh nhẩn.Tạp chí Y học Việt Nam, 10:27-36.

2. Kim SY, Nam SM, Park ES, Kim YB (2019). Evaluation of one-point fixation forzygomaticomaxillary complex fracturesusing a threedimensionalphotogrammetric analysis. Journal of Otolaryngology - Head and Neck Surgery 48:36.

3. Wu C-M, Chen Y-A, Liao H-T, Chen C-H, Pan C-H, Chen C-T (2018). Surgical treatment of isolated zygomaticfracture: Outcome comparison between titanium plate and bioabsorbable plate. Asian Journal of Surgery 41(4):370-376.

4. Tripathi N, Goyal M,Mishra B, Dhasmana S (2020). Zygomatic complex fracture: A comparative evaluation of stability using titanium and bio-resorbable plates as one point fixation.Natl J Maxillofac Surg. 4(2):181-187.

5. Kim JH, Kim JS, Oh DY, Jun JJ, Rhie JW, Moon SH (2020). Efficacy of Altered Two-Point Fixation in Zygomaticomaxillary Complex Fracture.BioMed Research International Volume 2020, Article ID 8537345.

6. Sukegawa S, Kanno T, Nagano D, Shibata A, Sukegawa-Takahashi Y, Furuki Y (2016). The Clinical Feasibility of Newly Developed Thin Flat Type Bioresorbable Osteosynthesis Devices for the Internal Fixation of Zygomatic Fractures: Is There a Difference in Healing Between Bioresorbable Materials and Titanium Osteosynthesis?] Craniofac Surg 27:2124-2129.

\title{
KẾT QUẢ PHẪU THUÂTT TẠO HÌNH KHE HỞ MÔI MộT BÊN TẠI BÊ̂NH VIỆN TRUNG ƯƠNG THÁI NGUYÊN
}

\section{TÓM TẮT ${ }^{10}$}

Mục tiêu: Đánh giá kết quả phẫu thuật tạo hình khe hở môi một bên tại Bệnh viện Trung Ưđ̛ning Thái Nguyên năm 2019-2020. Đối tượng và phương pháp: Nghiên cứu can thiệp lâm sàng không đối chứng trên 36 bệnh nhân $7-28$ tháng tuổi (27 nam, 9 nữ) trong nghiển cứu được tiến hành khám đánh giá

\footnotetext{
*Trường Đại học Y Dược Thái Nguyên

**Trường Đại học Kỹ thuật Y tế Hải Dương

Chịu trách nhiệm chính: Nguyễn Văn Ninh

Email: nguyenvanninh@tump.edu.vn

Ngày nhận bài: 1/3/2021
}

Ngày phản biên khoa họ: $26 / 3 / 2021$

Ngày duyệt bài: 9/4/2021

\section{Nguyễn Văn Ninh*, Lê Thị Hòa*, Vũ Đình Tuyên**}

tình trang khe hở môi và được tiến hành phẫu thuật tạo hình môi theo phương pháp Millard cải tiến. Bệnh nhân được khám, đánh giá và chăm sóc sau phẫu thuật tại bệnh viện và tái khám sau phẫu thuât 3 tháng, $\dot{6}$ tháng theo thang điểm Mortier. Kết quá và kết luận: $100 \%$ bệnh nhân không gặp các biến chứng sớm: chảy máu sau mổ, nhiễm trùng vết mổ, bục chỉ vết mổ, tụ máu bầm tím tại chỗ, đầu vạt/vạt bị hoại tử. Sau phẫu thuật 3 tháng, 6 tháng: 83,33\% bênh nhân đạt kết quả tốt trong đó: $86,11 \%$ môi trẳng cân đối, $100 \%$ nhân trung cân đối, 66,67\% môi đỏ cân đối, $100 \%$ không có lỗ dò và khuyết hổng thứ phát. Tỉ lệ sẹo dãn thẩm mĩ, giấu seo tốt sau phẫu thuật 3 tháng là $75 \%, 6$ tháng là $86,11 \%$.

Tư khóa: Khe hở môi một bên, Millard cải tiến, Mortier 


\section{SUMMARY \\ THE RESULT SURGICAL UNILATERAL CLEFT LIP REPAIR IN THAI NGUYEN NATIONAL HOSPITAL}

Objective: Assess the result of 36 patients surgical unilateral cleft lip at the Odonto-stomatology Dep of Thai Nguyen National Hospital from 2019 to 2020. Subjects and methods: A randomized clinical trial of 36 patients 7 - 28 months old ( 27 boys, 9 girls) in the study were conducted to assess the state of the cleft lip and underwent lip-shaping surgery according to the Millard method improvements. Patients were examined, assessed and cared for after surgery at the hospital and re-examined after 3 months, 6 months after surgery according to Mortier scale. Results and conclusion: The rate of post-operation early complications was $0 \%$. Post- operation, Patients weren't postoperative bleeding, wound infection, wound podium, hematoma, bruising on the spot, necrotic flap head / flap. In three month and six month post - operation: the percentage of good result was $83.33 \%$, of which: $86.11 \%$ balanced white lips, $100 \%$ balanced average kernel, $66.67 \%$ balanced red lips, $100 \%$ no with a gaps and a secondary flaw. The rate of cosmetic dilated scars, good hiding scars in three month post - operation is $75 \%$, in six month post - operation is $86.11 \%$.

Key words: Unilateral lip cleft, Improved Millard, Mortier

\section{I. ĐẶT VẤN ĐỀ}

Khe hở môi là bệnh lý bẩm sinh có tỷ lệ khá cao $1 / 600$ đến $1 / 1000$ trẻ, trong đó có thể khe hở môi đơn thuần hoặc kết hợp với khe hở vòm miệng. Bệnh nhân bị khe hở mồi gây ra những khuyết hổng về cấu trúc giải phẫu môi, làm gián đoạn sự liên tục của môi trên ảnh hưởng nặng nề tới thẩm mỹ và chức năng ăn uống, phát âm và ảnh hưởng muộn hơn lên sự phát triển khuôn mặt [1],[2],[3].

Để đáp ứng nhu cầu điều trị ngày một cao về chất lượng, đòi hỏi một kế hoạch điều trị toàn diện từ lúc trẻ mới sinh ra đến nhiêu năm sau phẫu thuật, đồng thời có sự phối hợp nhiều chuyên khoa như nhi khoa, tai mũi họng, răng hàm mặt, phục hồi chức năng $[3],[4],[5],[6]$. Trong đó, phẫu thuật tạo hình đóng kín khe hở môi đóng vai trò then chốt. Tại Việt Nam, trong nhiều năm nay với mục đích phục hồi hình thể môi, tái tạo và sửa chữa những biến dạng mũi các nhà lẩm sàng đã áp dụng đa dạng và linh hoạt các phương pháp phẫu thuật: Phương pháp Millard cải tiến, Tennison, Onizuka cải tiến...và đạt được kết quả cao[5],[7],[8].

Khoa Răng Hàm Mặt - Bệnh viện Trung Ương Thái Nguyên là một trong những địa chỉ tin cậy ở khu vực Miền Bắc trong phẫu thuật tạo hình khe hở mổi, song chưa có nghiên cứu nào đánh giá kết quả sau phẫu thuật. Do đó, chúng tôi tiến hành nghiên cứu này với mục tiêu: Đánh giá kêtt quả phẫu thuật tạo hinh khe hở môi một bên tại Bệnh viện Trung ương Thái Nguyên năm 20192020.

\section{II. ĐỐI TƯỢNG VÀ PHƯƠNG PHÁP NGHIÊN CỨU}

2.1. Đối tượng nghiên cứu: Trẻ có khe hở môi một bên đển khám và điều trị tại khoa Răng Hàm Mặt Bệnh viện Trung Ương Thái Nguyên.

2.2. Địa điểm và thời gian nghiên cứu: Khoa Răng Hàm Mặt Bệnh viện trung ương Thái Nguyên từ tháng 1/2019 đến 12/2020.

\subsection{Phương pháp nghiên cứu:}

- Phương pháp nghiên cứu: Nghiên cứu can thiệp lâm sàng không đối chứng.

- Tiêu chuẩn chọn mẫu: Tiêu chuẩn lựa chọ: Trẻ có đủ điều kiện sức khỏe tiến hành phẫu thuật khe hở môi một bên thì đầu được gia đình đồng ý tham gia nghiên cứu. Tiêu chuẩn loại trừ: Trẻ không đến tái khám theo lịch hẹn.

- Cõ̃ mẫu tính theo công thức:

$$
\mathrm{n}=\mathrm{Z}^{2}(1-\alpha / 2) \frac{\mathrm{p}(1-\mathrm{p})}{\mathrm{d}^{2}}
$$

Trong đó: $\mathrm{Z}_{(1-\alpha / 2)}=1.96, \alpha=0.05, \mathrm{~d}=0.1, \mathrm{p}$ $=0.914$ (Theo nghiên cứu của tác giả Nguyê̂n Hoàng Minh năm 2016: tỷ lệ đạt kết quả tốt sau phẫu thuật tạo hình mổi mũi thì đầu là 91,4\%)[4]. Cỡ mẫu tính được là 30 bệnh nhân. Nghiên cứu thực hiện trên 36 bệnh nhân.

- Cách chọn mẫu: Chọn toàn bộ trẻ đến khám và điều trị đạt tiêu chuẩn chọn mẫu vào nghiên cứu.

- Phương pháp phẫu thuật: Phương pháp Millard cải tiến

- Biến số, chỉ số nghiên cứu: thông tin nhân khẩu học; khám lâm sàng phân loại khe hở môi trước phẫu thuật và đánh giá kết quả phẫu thuật sau 3 tháng, 6 tháng theo tiêu chí thang điểm Mortier [7].

- Kỹ thuật thu thập số liệu: Thông tin nhân khẩu học được lấy từ bệnh án điều trị, khám lâm sàng trước và sau phẫu thuật được thực hiện bởi bác sĩ chuyên khoa răng hàm mặt.

2.4. Xử lý số liệu: Số liệu được xử lý bằng các thuật toán thống kê y học có sử dụng phần mềm SPSS 16.0.

2.5. Đạo đức trong nghiên cứu: Nghiên cứu được tiến hành đảm bảo các qui định về đạo đức trong nghiên cứu y sinh học và được thực hiện sau khi đã được Hội đồng đạo đức Trường Đại học Y Dược-Đại học Thái Nguyên thông qua.

\section{KẾT QUẢ NGHIÊN CỨU}

Nghiên cứu can thiệp lâm sàng không đối 
chứng được thực hiện trên 36 trẻ 7- 28 tháng tuổi (27 trẻ nam, 9 trẻ nữ) chủ yếu là người dân tộc thiểu số đến từ các tỉnh miền Bắc Việt Nam, kết quả nghiên cứu cho thây:

3.1. Phân loại khe hở môi

Bảng 1. Phân loại khe hở môi

\begin{tabular}{|c|c|c|}
\hline $\begin{array}{c}\text { Độ nă̆ng khe } \\
\text { hở }\end{array}$ & $\begin{array}{c}\text { Số bệnh nhân } \\
(\mathbf{n})\end{array}$ & $\begin{array}{c}\text { Tỷ lệ } \\
\mathbf{( \% )}\end{array}$ \\
\hline Nặng & 21 & 58,33 \\
\hline Trung bình & 13 & 36,11 \\
\hline Nhẹ & 2 & 5,56 \\
\hline Tống & $\mathbf{3 6}$ & $\mathbf{1 0 0}$ \\
\hline
\end{tabular}

Nhận xét: Phân loại khe hở môi theo Mortier, hơn một nửa số trẻ trong nghiên cứu có khe hở môi mức độ năng $(58,33 \%)$, số ít trẻ có khe hở môi mức nhe $(5,56 \%)$.

3.2. Kết quả đîêu trị. Sau phẫu thuật khe hở môi, $100 \%$ bệnh nhân không gặp các biến chứng sớm: chảy máu sau mổ, nhiểm trùng vết mổ, bục chỉ vết mổ, tụ máu bầm tím tại chỗ, đầu vạt/vạt bị hoại tử. Tái khám sau 3 tháng, 6 tháng nhận thấy:

Bảng 2. Kết quả tạo hình môi trên

\begin{tabular}{|c|c|c|c|}
\hline \multirow{2}{*}{\multicolumn{2}{|c|}{$\begin{array}{l}\text { Các tiêu chí đánh giá } \\
\text { hình thể môi trên }\end{array}$}} & \multicolumn{2}{|c|}{$\begin{array}{c}\text { Kết quả sau phâu } \\
\text { thuật }\end{array}$} \\
\hline & & 3 tháng & 6 tháng \\
\hline \multirow{4}{*}{$\begin{array}{l}\text { Môi đỏ } \\
(n=36)\end{array}$} & Cân đối & $24(66,67)$ & $24(66,67)$ \\
\hline & $\begin{array}{l}\text { Môi đỏ bên } \\
\text { khe hở dày }\end{array}$ & $5(13,89)$ & $5(13,89)$ \\
\hline & Khuyết chữ V & $6(16,67)$ & $6(16,67)$ \\
\hline & $\begin{array}{l}\text { Đường viền } \\
\text { môi khồng đêu }\end{array}$ & $1(2,77)$ & $1(2,77)$ \\
\hline \multirow{4}{*}{$\begin{array}{c}\text { Ngách tiền } \\
\text { đình }(\mathrm{n}=36) \\
\text { Tỷ lệ môi } \\
\text { trắng } \\
(\mathrm{n}=36)\end{array}$} & Cân đối & $30(83,33)$ & $30(83,33)$ \\
\hline & & $6(16,67)$ & $6(16,67)$ \\
\hline & Cân đối & $31(86,11)$ & $31(86,11)$ \\
\hline & $\begin{array}{l}\text { Ngắn so với } \\
\text { bên lành }\end{array}$ & $5(13,89)$ & $5(13,89)$ \\
\hline \multirow{2}{*}{$\begin{array}{l}\text { Nhân trung } \\
(n=36)\end{array}$} & Cân đối & $36(100)$ & $36(100)$ \\
\hline & Lệch & $0(0)$ & $0(0)$ \\
\hline
\end{tabular}

Nhận xét: Kết quả phẫu thuật tạo hình môi đạt kết quả cao và không khác biệt giữa sau phẫu thuật 3 tháng và 6 tháng, tỉ lệ cân đối làn môi đỏ là $66,67 \%$, môi trắng là $86,11 \%$, ngách tiền đình là $83,33 \%$, nhân trung là 100\%.

Bảng 3. Hình thể giải phẫu mũi

\begin{tabular}{|c|c|c|c|}
\hline \multirow{2}{*}{\multicolumn{2}{|c|}{$\begin{array}{l}\text { Tiêu chí đánh giá hình } \\
\text { thể mữi }\end{array}$}} & \multicolumn{2}{|c|}{$\begin{array}{c}\text { Kết quả sau phấu } \\
\text { thuật }\end{array}$} \\
\hline & & & \\
\hline \multirow{3}{*}{$\begin{array}{l}\text { Đồ rộng } \\
\text { nền mũi } \\
(n=36)\end{array}$} & Cân đối & $31(86,11)$ & $31(86,11)$ \\
\hline & $\begin{array}{l}\text { Rộng hơn bên } \\
\text { lành }\end{array}$ & $3(8,33)$ & $3(8,33)$ \\
\hline & Hẹp hơn bên lành & $2(5,56)$ & $2(5,56)$ \\
\hline
\end{tabular}

\begin{tabular}{|c|c|c|c|}
\hline $\begin{array}{l}\text { Trụ mũi } \\
(n=36)\end{array}$ & $\begin{array}{c}\text { Cân đối } \\
\text { Lệch trụ mũi }\end{array}$ & $\frac{24(66,67)}{12(33,33)}$ & \\
\hline \multirow{3}{*}{$\begin{array}{l}\text { Cánh } \\
\text { mũi } \\
(n=36)\end{array}$} & Cân đối & & \\
\hline & & & $3(8,33$ \\
\hline & $\begin{array}{c}\text { Cánh mũi bị kéo } \\
\text { xuống dưới }\end{array}$ & $\begin{array}{c}4 \\
(11,11)\end{array}$ & \\
\hline
\end{tabular}

Nhân xét: Sau phẫu thuật 3 tháng, đa số trẻ có độ rộng nền mũi cân đối $(86,11 \%)$, cánh mũi cân đối $(83,33 \%)$, tỉ lệ trẻ có trụ mũi cân đối thấp hơn $(66,67 \%)$. Hình thể mũi sau phẫu thuật 6 tháng có kết quả thấp hơn so với sau phấu thuât 3 tháng về tiêu chí cánh mũi.

Bảng 4. Tình trạng sẹo mổ và lỗ dò thứ phát

\begin{tabular}{|c|c|c|c|}
\hline \multirow{2}{*}{\multicolumn{2}{|c|}{$\begin{array}{l}\text { Tiêu chí đánh giá séo và } \\
\text { Î̂́ dò thứ phát }\end{array}$}} & \multicolumn{2}{|c|}{$\begin{array}{c}\text { Kết quả sau phẩu } \\
\text { thuật }\end{array}$} \\
\hline & & \multirow{2}{*}{\begin{tabular}{|c|}
3 tháng \\
n(\%)
\end{tabular}} & \multirow{2}{*}{\begin{tabular}{|c|}
$\begin{array}{c}\text { 6 tháng } \\
\text { n(\%) }\end{array}$ \\
$5(13,89)$ \\
\end{tabular}} \\
\hline \multirow[b]{2}{*}{$\begin{array}{c}\text { Sẹo } \\
(n=36)\end{array}$} & Sẹo lồi & & \\
\hline & $\begin{array}{l}\text { Seoo dãn } \\
\text { thẩm mỹ } \\
\text { giấu sẹo tốt }\end{array}$ & $27(75)$ & $31(86,11)$ \\
\hline \multirow{2}{*}{$\begin{array}{c}\text { Lố dò hay tổn } \\
\text { khuyết thứ phát } \\
(n=36)\end{array}$} & Có & $0(0)$ & $0(0)$ \\
\hline & Không & $\begin{array}{c}36 \\
(100)\end{array}$ & $\begin{array}{c}36 \\
(100)\end{array}$ \\
\hline
\end{tabular}

Nhận xét: Sau phẫu thuật, tî lệ sẹo dãn thẩm mỹ, giấu sẹo tốt tăng lền theo thời gian (sau 3 tháng: $75 \%$, sau 6 tháng $86,11 \%$ ). $100 \%$ bệnh nhân không có lỗ dò hay tổn thương khuyết thứ phát.

Bảng 5. Kết quả phẫu thuật

\begin{tabular}{|c|c|c|}
\hline $\begin{array}{c}\text { Kết quả sau } \\
\text { phẫu thuật }\end{array}$ & $\begin{array}{c}\mathbf{3} \text { tháng } \\
\mathbf{n}(\mathbf{\%})\end{array}$ & $\begin{array}{c}\mathbf{6} \text { tháng } \\
\mathbf{n}(\mathbf{\%})\end{array}$ \\
\hline Tốt & $30(83,33)$ & $30(83,33)$ \\
\hline Trung bình & $6(16,67)$ & $6(16,67)$ \\
\hline Kém & 0 & 0 \\
\hline Tổng & $\mathbf{3 6 ( 1 0 0 \% )}$ & $\mathbf{3 6 ( 1 0 0 \% )}$ \\
\hline
\end{tabular}

Nhận xét: Dựa trên tống điểm các tổn khuyết sau phẫu thuật 3 tháng, 6 tháng cho kết quả chung giống nhau với tỷ lệ tốt đạt 83,33\%; không có bệnh nhân đạt kết quả kém.

\section{BÀN LUÂ̂N}

Qua nghiển cứu 36 bệnh nhân phẫu thuật tạo hình khe hở môi một bên được phẫu thuật tại Bệnh viện Trung ương Thái Nguyên chúng tồi nhận thấy số bệnh nhân nam 27/36 bệnh nhân chiếm tỷ lệ $75 \%$, nữ chiếm $25 \%$, nghiên cứu này phù hợp với những nghiên cứu[2], [3], [4], [5], [6]. Điều này nói lên trẻ trai mắc dị tật nhiêu hơn trẻ gái.

ở Việt Nam, thời điểm phẫu thuật đóng khe hở môi thường từ 4- 6 tháng tuổi trở lên khi trẻ đạt điều kiên sức khỏe và gây mê. Trong nghiên cứu của chúng tôi bệnh nhân có độ tuổi từ 7 
tháng đến 28 tháng, đa số là dưới 1 tuổi phù hợp với nghiên cứu của các tác giả khác [2], [3], [4],[8]. Tuy nhiên hiện nay chỉ định phẩu thuật đã có nhiều thay đổi đó là xu hướng can thiệp sớm cho trẻ vào khoảng 4 tuần đến 6 tuần tuổi theo nghiên cứu của Đặng Hoàng Thơm [5] cho kết quả tốt khi điều kiện về gây mê và chăm sóc sau phẫu thuật tốt hơn.

Theo bảng 1 , tỷ lệ bệnh nhân trong nhóm mức độ nặng chiếm ưu thế $58,33 \%$ và có 2 bệnh nhân thuộc nhóm mức độ nhẹ. Tỷ lệ bệnh nhân trong nhóm mức độ nặng của chúng tôi thấp hơn so với nghiên cứu của Nguyễn Hoàng Minh $(66 \%)$ và Rajankikanth $(75 \%)$ do nghiên cứu của các tác giả lựa chọn trẻ có khe hở môi một bên toàn bộ [4], [6].

- Đánh giá các tai biến và biến chứng sau phẫu thuật. Trong nghiên cứu của chúng tôi, 100\% bệnh nhân không có biến chứng sớm sau phẫu thuật, $100 \%$ bệnh nhân liền thương tốt sau mổ; vạt da được nuôi dưỡng tốt. Không có biểu hiện bục chỉ hay nhiễm trùng và tụ máu tại vết mổ. Nghiên cứu của chúng tôi có kết quả tương tự nghiên cứu của Nguyễn Hoàng Minh [4]. Nghiên cứu của Đăng Hoàng Thơm cho thãy 4/76 bệnh nhân viêm và toác vết mổ ở phần niêm mạc miệng [5]. Để đạt được kết quả lành thương và vạt nuôi dưỡng tốt, trong quá trình phẫu thuật chúng tôi bóc tách từng lớp giải phẫu, tránh dập nát tổ chức, cầm máu kỹ, khâu phục hồi đúng lớp giải phẫu, tránh để lại khoang ảo đồng thời đảm bảo việc chăm sóc hẫu phẫu tốt.

- Đánh giá kết quả phẫu thuật sau 3 tháng và 6 tháng. Kết quả lành thương sau phẫu thuật 3 tháng, 6 tháng của môi đỏ, ngách tiền đình, môi trắng, nhân trung, nền mũi, trụ mũi là như nhau. Kết quả hình thể seo, cánh mũi sau phẫu thuật có sự thay đổi theo thời gian.

Đánh giá các đặc điểm giải phẫu môi trên và ngách tiền đình sau phẫu thuật: Tỷ lệ làn môi đỏ cân đối là $66,67 \%$. Tỷ lệ này của chúng tôi thấp hơn nghiên cứu của Nguyễn Hoàng Minh [4] với tỷ lệ $71,4 \%$ và nghiên cứu Đặng Hoàng Thơm [5]. Kết quả nghiên cứu của chúng tôi đat tỷ lệ làn môi đỏ cao hơn nghiên cứu của Nguyền Văn Minh [8], Rajanikanth [6]. Tổn thương môi đỏ hay gặp nhất là khuyết hình chữ $V$ hay khuyết dạng huýt sáo cũng tương tự như các nghiên cứu của các tác giả khác [3], [4], [5], [6].

Trong phẫu thuật môi thì đầu ở những bệnh nhân được chẩn đoán khe hở ở mức độ nặng và trung bình chúng tôi có áp dụng phẫu thuật tạo ngách tiền đình đây là điều kiên tốt để bít lỗ thông từ ngách tiền đình lên nền mũi và tạo thuận lợi cho ghép xương ổ răng sau này chúng tôi sử dụng vạt niêm mạc ở bờ trong khe hở khâu vào gai mũi trước. Trong nghiên cứu của chúng tôi tỷ lệ bệnh nhân có ngách tiền đình cân đối là $83,33 \%$ thấp hơn nghiên cứu của Nguyễn Hoàng Minh là 91,4\% [4].

Trong nghiên cứu, chúng tôi sử dụng phương pháp Millard cải tiến cho thấy kết quả tốt trong việc bù chiều cao da môi thiếu hụt bên khe hở, đồng thời sử dụng vạt chữ $Z$ trên đường viền da môi đỏ và bóc tách tốt cơ vòng môi khỏi chỗ bám lạc chỗ ở gai mũi trước và chân trụ mũi do đó khâu phục hồi tốt cơ vòng môi theo đúng sinh lý. Chính vì vậy mà kết quả nghiên cứu thấy tỷ lệ môi trắng cân đối chiếm $86,11 \%$ thấp hơn kết quả nghiên cứu của Nguyễn Hoàng Minh [4] với $91,4 \%$.

Sau 3 tháng và 6 tháng tái khám $100 \%$ bệnh nhân có nhân trung cân đối. Sau 6 tháng, tỷ lệ sẹo dãn thẩm mỹ, giấu sẹo tốt là $86,11 \%$. Tỷ lệ sẹo lồi giảm dần theo thời gian tại thời điểm sau 3 tháng là $25 \%$ giảm còn $13,89 \%$ sau 6 tháng. Tỷ lệ sẹo dãn thẩm mỹ, giấu sẹotốt của chúng tôi cao hơn các nghiên cứu của Nguyễn Văn Minh [8]; thấp hơn kết quả nghiên cứu của Nguyễn Hoàng Minh [4] và Rajanikanth [6]. Các vạt da được nuôi dưỡng tốt sau mổ giúp sẹo dã̃n, ít gây co kéo và không ảnh hưởng đến sự tự nhiên của nhân trung. Trong nghiên cứu của chúng tôi, $100 \%$ bệnh nhân sau phẫu thuật không có lỗ rò và tổn khuyết thứ phát, kết quả này tương tự như nghiên cứu của tác giả Nguyễn Hoàng Minh [4], Nguyễn Văn Minh [8] và Rajankikanth [6].

Sau phẫu thuật 3 tháng và 6 tháng đạt tỷ lệ nền mũi cân đối là $86,11 \%$. Tỷ lệ cánh mũi cân đối từ 83,33\% sau 3 tháng giảm xuống 77,78\% sau 6 tháng. Kết quả của chúng tôi cao hơn nghiên cứu của Nguyễn Văn Minh [8] và Rajanikanth [6] nhưng tương tự kết quả nghiên cứu của Nguyển Hoàng Minh [4] với tỷ lệ cánh mũi cân đối sau 6 tháng là 77,1\%. Trong đó nghiên cứu của Nguyễn Hoàng Minh [4] và Rajanikanth [6] đều sử dụng phương pháp Millard cải tiến kết hợp tạo hình mũi thì đầu còn nghiên cứu của Nguyễn Văn Minh[8] mới quan tâm đến tạo hình môi, chưa quan tâm đến tạo hình mũi. Chúng tôi sử dụng phương pháp phẫu thuật tạo hình Millard cải tiến và có can thiệp mũi trong trường hợp khe hở mức độ nặng và trung bình. Tỷ lệ bệnh nhân có trụ mũi cân đối trong nghiên cứu của chúng tôi là $66,67 \%$, tỷ lệ trụ mũi lệch $33,33 \%$. Tác giả Nguyễn Hoàng Minh có kết quả tương tự về tỷ lệ trụ mũi lệch 
chiếm 40\%[4]. Trong nghiên cứu của tác giả Rajanikanth, tỷ lệ trụ mũi cân đối sau phẫu thuật là 35\%, thấp hơn của chúng tôi, điều này có thể do trong nghiên cứu của tác giả, nhóm khe hở nặng chiếm tỷ lệ cao hơn của chúng tôi [6].

Kết quả chung sau 3 tháng và 6 tháng phẫu thuật đạt loại tốt chiếm 83,33\%: kết quả trung bình chiếm: 16,67\%; Không có bệnh nhân có kết quả kém. Tỷ lệ kết quả tốt sau phẫu thuật của chúng tôi thấp hơn nghiên cứu của Nguyễn Hoàng Minh [4] và Rajanikanth [6] và tương tự nghiên cứu của Nguyễn Văn Minh [8]. Nghiên cứu của Taiwo và cộng sự tại một bệnh viện thực hành tại Nigeria chỉ đạt mức kểt quả tốt sau phẫu thuật là $67,9 \%$ thấp hơn kết quả nghiên cứu của chúng tôi do các đối tượng phầu thuật gồm trẻ có khe hở môi một bên và khe hở hai bền [3].

\section{KẾT LUÂN}

- Phân loại khe hở môi trước phẫu thuật: 58,33\% mức độ nặng, 36,11\% mức độ trung bình, 5,56\% mức độ nhẹ.

- 100\% bệnh nhần không gặp các biến chứng sớm: chảy máu sau mổ, nhiểm trùng vết mổ, bục chỉ vết mổ, tụ máu bầm tím tại chỗ, đầu vạt/vạt bị hoai tử.

- Sau phẫu thuật 3 tháng, 6 tháng: 83,33\% bênh nhân đạt kết quả tốt trong đó: $86,11 \%$ môi trắng cân đối, $100 \%$ nhân trung cân đối, $66,67 \%$ môi đỏ cân đối, $100 \%$ không có lỗ dò và khuyết hổng thứ phát. Tỉ lệ sẹo dãn thẩm mĩ, giấu sẹo tốt sau phẫu thuật 3 tháng là $75 \%, 6$ tháng là $86,11 \%$.

\section{TÀI LIÊU THAM KHẢO}

1. Nguyễn Bắc Hùng (2005), Phẫu thuật tạo hình, Nhà xuất bản Y hoc, Hà Nôii, trang 143-148

2. Adekunle Moses Adetayo, Modupe Olushola Adetayo, Wasiu Lanre Adeyemo et al. (2019) "Unilateral cleft lip: evaluation and comparison of treatment outcome with twosurgical techniques based on qualitative (subject/guardian and professional) assessment" J Korean Assoc Oral Maxillofac Surg 2019;45:141-151

3. Taiwo 0. Abdurrazaq, Adeyemi 0. Micheal, Adeyemo W. Lanre, et la (2013) "Surgical outcome and complications following cleft lip and palate repair in a teaching hospital in Nigeria" African Journal of Paediatric Surgery, OctoberDecember 2013, Vol 10, Issue 4, p345-357

4.Nguyê̂n Hoàng 'Minh (2016) "Kết quả tạo hình khe hở môi một bên toàn bộ bằng phương pháp Millard cải tiến kết hợp tạo hình mũi thì đầu" Kỳ yếu Hội nghị Khoa học - Công nghệ tuổi trẻ các trường Đại học, Cao đẳng Y - Dược Việt Nam lần thứ XVIII năm 2016, tr 268-271.

5. Đăng Hoàng Thơm, Nguyễn Thanh liêm (2013) "Đ́ánh giá kết quả phấu thuât tao hình khe hở môi một bên ở trẻ sơ sinh bằng kỹ thuật Onizuka cải tiển" Tap chí Y học TP Hồ Chí Minh, chuyên đề ngoại nhi, tập 17, số 3 năm 2013, trang 1-7.

6. Rajanikanth B.R., Krishna S.R., Sharma S.M., ete. (2012). Assessment of Deformities of the Up and Nose in Cleft Lip Alveolus and Palate Patients by a Rating Scale. J. Maxiilofac. Oral Surg, 11,38 - 46.

7. Mortier M.A. (1997). Evaluation of the results of cleft lip and palate surgical treatment. Cieft palate - craniofacial journal, 34, 247- 255.

8. Nguyễn Văn Minh (2009). Đánh giá vai trò tạo hinh chữ $Z$ ở trên đường viền da -môi đỏ trong phương pháp Millard mổ khe hở môi một bên toàn bộ. Luận văn tốt nghiệp thạc sỹ, Đại học Y Hà Nội.

\section{HIỆU QUẢ ĐIỀU TRI NộI NHA TRÊN RĂNG Có SANG THƯƠ'NG QUANH CHÓP CỦA XI-MĂNG TRÁM BÍT ỐNG TỦY NỀN CALCIUM SILICATE}

\section{TÓM TẮT}

Mục tiêu: Đánh giá mức độ đau (đau tự phát và đau khi ăn nhai) sau trám bít hệ thống ống tủy bằng Xi-măng nền Calcium Silicate tại thời điểm $6 \mathrm{~h}, 12 \mathrm{~h}$, $24 \mathrm{~h}$ và $72 \mathrm{~h}$. Đánh giá kích thước sang thương quanh chóp trên X-quang tại thời điểm ngay sau khi trám bít hệ thống ống tủy, 3 tháng, 6 tháng. Đối tượng và phương pháp nghiên cứu: nghiên cứu báo cáo

*Bệnh viện Quận 1, Tp.HCM

**Đai hoc Y Dước Thành phố Hồ Chí Minh

Chịu trách nhiệm chính: Trân Xuân Vĩnh

Email: vinhdentist@yahoo.com

Ngày nhận bài: 22.2.2021

Ngày phản biên khoa học: 22.3.2021

Ngày duyệt bài: 2.4 .2021

\section{Nguyễn Phan Hoài Mỹ*, Trần Xuân Vĩnh**}

hàng loạt $c a$, thực hiện trên 16 răng một chân có bệnh lý sang thương quanh chóp, được trám bít hệ thống ống tủy bằng Xi-măng nền Calcium Silicate của 15 bệnh nhân (trên 18 tuổi) tại Bệnh viện Quận 1 trong thời gian từ tháng 07/2020 đến 03/2021. Kết quả: Đối tượng nghiên cứu có độ tuổi trung bình là 50,6 tuổi, nữ chiếm $43,7 \%$. Có $37,5 \%$ bênh nhân có áp-xe quanh chóp răng, sau 3 tháng $100 \%$ các răng không còn áp-xe, không còn dấu chứng lâm sàng. Mức độ đau tự phát và đau khi ăn nhai trung bình của bênh nhân cao nhất là ngay sau khi trám bít hê thống ống tủy theo thang đo VAS (3,8 điểm và 3,9 điểm), sau đó giảm dần ở các thời điểm sau đó 6 giơo, 12 giớ 24 giờ và thấp nhất là sau 72 giờ trám bít hệ thống hệ thống ống tủy ( 0 điểm). Diện tích trung bình vùng thấu quang đo bằng phần mềm ImageJ và đánh giá tình trạng sang thương quanh chóp trên X-quang theo 